\title{
Evaluation of the Knowledge, Attitudes and Practices of the Hospital Staff in the Management of High Blood Pressure in Conakry
}

\author{
Ibrahima Sory 2 Sylla $^{*}$, Djibril Sylla², Elhadj Yaya Baldé1, Aissatou Barry' ${ }^{1}$, Mabintou Condé1, \\ Mamadou Bachir Bah1, Mamadou Aliou Baldé1, Sana Samoura1, Ibrahima Sory Barry¹, \\ Mariame Béaovogui1, Mamadou Dadhi Baldé1, Mamadi Condé1 \\ ${ }^{1}$ Cardiology Department, Hospital Conakry, Conakry, Guinea \\ ${ }^{2}$ Medico-Surgical Emergencies Department, Hospital Donka, Conakry, Guinea \\ Email: ^ibsosyl@yahoo.fr
}

How to cite this paper: 2 Sylla, I.S., Sylla, D., Baldé, E.Y., Barry, A., Condé, M., Bah, M.B., Baldé, M.A., Samoura, S., Barry, I.S., Béaovogui, M., Baldé, M.D. and Condé, M. (2019) Evaluation of the Knowledge, Attitudes and Practices of the Hospital Staff in the Management of High Blood Pressure in Conakry. World Journal of Cardiovascular Diseases, 9, 354-359.

https://doi.org/10.4236/wjcd.2019.95031

Received: April 6, 2019

Accepted: May 27, 2019

Published: May 30, 2019

Copyright $\odot 2019$ by author(s) and Scientific Research Publishing Inc. This work is licensed under the Creative Commons Attribution International License (CC BY 4.0).

http://creativecommons.org/licenses/by/4.0/

\begin{abstract}
Introduction: High blood pressure is a real public health problem affecting more than one in three adults. The objective of this study was to evaluate the level of knowledge, attitudes and practices of health care personnel in the management of hypertension in Conakry. Methods: Descriptive transversal study of 6 months, from April 20, 2018 to September 20, 2018, which took place in the internal medicine departments of the two university hospital centers (CHU) of Conakry (Donka and Ignace Deen). The study population consisted of general practitioners and specialists, practicing in both departments for at least two years and who agreed to submit to our questionnaire. Results: At the end of the study, we included 140 doctors, $61 \%$ at Donka University Hospital and 39\% at Ignace Deen University Hospital. The predominance was male with 113 men for 27 women with a sex ratio $\mathrm{H} / \mathrm{F}=4.18$. General practitioners were the most represented with $95 \%$ against $5 \%$ specialists. Sixty-four percent of physicians gave an exact definition of hypertension, $56 \%$ of physicians confirmed the diagnosis of hypertension after 2 to 3 consultations. $19 \%$ offered monotherapy as first-line treatment, only $72 \%$ said that the duration of Antihypertensive treatment was for life. Conclusion: These results demonstrate that it is essential to reflect on our daily practices for a good improvement in the quality of care for patients.
\end{abstract}

\section{Keywords}

High Blood Pressure, Knowledge, Attitudes and Practices, Conakry 


\section{Introduction}

Cardiovascular diseases are a major health problem around the world [1]. High blood pressure (HTA) is a common disease, contributing significantly to cardiovascular and renal morbidity and mortality. Its consequences can be limited by structured management [2]. It is responsible for $18 \%$ of deaths in rich countries and $45 \%$ of cardiovascular deaths, generates severe disabilities related to stroke, dementia, heart failure and kidney failure chronic [3]. Over the past 50 years, many advances have continuously changed knowledge, management of hypertension, and added costs. Scholarly societies and national and international institutions have published guidelines for clinical practice in the area of hypertension for physicians. Nevertheless, a significant discordance persists between the recommended practices and those observed [2]. The objective of this study was to assess the level of knowledge, attitudes and practices of health care staff in the management of hypertension in Conakry.

\section{Methods}

It was a descriptive cross-sectional study of 6 months, from April 20, 2018 to September 20,2018, which took place in the internal medicine departments of the two Conakry UHCs (Donka and Ignace Deen). The study population consisted of general practitioners and specialists, practicing in both internal medicine departments for at least two years and who agreed to submit to our questionnaire. The dependent variable was the support for HTA. Each survey card included information about the doctor's qualification, place of work, knowledge of the definition of hypertension, cardiovascular risk factors, the diagnosis of hypertension, and the recommended minimum balance sheet. WHO, the impact of hypertension, the assessment of overall risk, the different therapeutic classes, blood pressure goals, the indication of lifestyle and dietary measures, indication for monotherapy, dual therapy and triple therapy, duration of antihypertensive treatment. The written consent of the doctors surveyed was obtained. The confidentiality of the data collected on the participants has been guaranteed.

The collected data was captured, processed and analyzed with Epi Data 3.1 software. The qualitative variables were expressed in percentage and the quantitative variables in average \pm standard deviation.

\section{Results}

At the end of the study, we included 140 doctors including $61 \%$ at Donka University Hospital and 39\% at Ignace Deen University Hospital. The predominance was male with 113 men for 27 women with a sex ratio $H / F=4.18$. General practitioners were the most represented with $95 \%$ against $5 \%$ specialists. Sixty-four percent $(64 \%)$ of physicians gave an accurate definition of hypertension. Four came seven percent (87\%) of the doctors took the blood pressure after 5 to 10 min of rest. Fifty-six percent (56\%) of the physicians confirmed the diagnosis of hypertension after 2 to 3 visits (Table 1 ). 
Table 1. Distribution of 140 physicians according to knowledge of the diagnosis of hypertension.

\begin{tabular}{ccc}
\hline Diagnostic & Effective & Percentage \\
\hline $\begin{array}{c}\text { HTA confirmed after } \\
2 \text { to 3 Consultations }\end{array}$ & 79 & 56.43 \\
$\begin{array}{c}\text { HTA confirmed after } \\
\text { consultation }\end{array}$ & 43 & 30.71 \\
$\begin{array}{c}\text { Self-measurement } \\
\text { Ambulatory } \\
\text { measurement } \\
\text { of blood pressure }\end{array}$ & 11 & 7.86 \\
Total & 7 & 5 \\
\hline
\end{tabular}

No doctor had three types of armbands (Obese, normal adult and child). Orthostatic hypotension was not sought in $100 \%$ of cases. Eighty-two percent (82\%) of physicians did not know the minimum recommended by WHO. Sixteen percent $(16 \%)$ of physicians had knowledge about cardiovascular risk stratification. Eightyfive percent (85\%) recommended dietary and hygiene measures. Nineteen percent (19\%) offered monotherapy as a first-line treatment, only $72 \%$ said the duration of antihypertensive therapy was for life.

\section{Discussion}

We carried out a descriptive cross-sectional study with the doctors of the two internal medicine departments of the two CHUs of conakry, over a period of 6 months.

As difficulties of this study, the refusal of some doctors to participate in the investigation.

The study involved 140 doctors, $61 \%$ of whom were doctors at Donka University Hospital and 39\% at Ignace Deen University Hospital. General practitioners were the most represented with $95 \%$. This high number of general practitioners is in line with the scarcity of postgraduate training centers in our country. The mean age of physicians was $43 \pm 5.2$ years, with male predominance and a ratio of $\mathrm{H} / \mathrm{F}=4.18$. This result is similar to that of Zahraoui M [4] in Morocco, which reported $56.67 \%$ of men and $43.33 \%$ of women. However, in a similar study in Mali, Menta I et al. had reported that women were the most represented. [5] According to the WHO, hypertension is defined as systolic blood pressure (SBP) $\geq 140 \mathrm{mmHg}$ and/or diastolic blood pressure (DBP) $\geq 90 \mathrm{mmHg}$ [6]. This definition has been given by more than half of the physicians. Data vary from country to country, Zahraoui $\mathrm{M}$ et al. [4] reported that $60 \%$ of physicians accurately defined HTA, whereas Dia MM et al. in Dakar, 56.5\% had a false definition [7]. The cardiovascular risk factors make it possible to evaluate the overall risk [8], it emerges in our study that active smoking was sought by $73 \%$ of doctors and type 2 diabetes by $46.3 \%$. In contrast to literature data, all physicians sought smoking 
and diabetes [4]. This shows that Guinean health care workers need ongoing training to improve the quality of care for this condition. The measurement of blood pressure is an important step in the diagnosis of hypertension. It is according to the tension figures that one decides whether or not the subject is hypertensive, or whether it is necessary to make a balance and a treatment. This measure must be carried out according to rigorous criteria. In our study $55 \%$ of physicians took blood pressure after a rest period of at least five minutes, sitting, lying down and both arms. Menta I et al. [5] reported a rate of $31.2 \%$. It should be noted that our sample consisted essentially of physicians (General Practitioners and Specialists). As for the diagnosis, 56.43\% of doctors made the diagnosis after 2 or 3 consultations. The data are contradictory in the literature and vary from one country to another [9] [10] [11]. Self-measurement and Ambulatory Blood Pressure Measurement (ABPM) can be used to correct misdiagnosis by excess or default, $7.86 \%$ of physicians cited self-measurement and only $5 \%$ of ABPM to make the diagnosis. Hypertension. This result shows that these two methods are still less recommended by the hospital staff. In our series, only 25 physicians or $17.86 \%$ claimed to have requested a minimum recommended by the WHO during the management of hypertension.

The initial assessment of the hypertensive patient aims to identify associated risk factors, target organ damage, cardiovascular or renal disease [8]. The benefit to be expected from an antihypertensive treatment is even greater than the cardiovascular risk is high. This led WHO to propose that absolute risk be taken into account in therapeutic decisions. In our study, 22 physicians of which the five specialists were $16 \%$ made this assessment. This shows that most physicians are more interested in blood pressure than in assessing overall risk. Less than $50 \%$ knew the target organs and the main complications, these pose a real problem in the management of hypertensive patients. The health and dietary measures were adopted from $140 / 90 \mathrm{mmHg}$ by a quarter of doctors, our result is much lower than those reported by some authors [12] [13]. However, lifestyle modifications can have a significant impact on the prevention of cardiovascular disease. It has been shown that they can effectively lower blood pressure [12]. This average decrease is $10 \mathrm{~mm} \mathrm{Hg}$ for systolic blood pressure and $5 \mathrm{~mm} \mathrm{Hg}$ for diastolic blood pressure [12]. Drug treatment was started with $80 \%$ of doctors from 150/90 mm $\mathrm{Hg}$. According to the literature, it is recommended to start treatment of hypertension with monotherapy or a fixed combination in one intention era [14]. This monotherapy was proposed by $18.6 \%$ of physicians, $49.28 \%$ indicated dual therapy in case of failure of monotherapy and only $50 \%$ recommended triple therapy after failure of dual therapy. In our series, $61 \%$ of physicians gave blood pressure goals (less than 140/90 mm Hg). The majority had opted for a lifetime treatment (lifestyle and dietary measures, drug treatment) or $72 \%$. However, $18 \%$ of physicians ordered discontinuation of antihypertensive therapy after blood pressure normalization, which could lead to often dramatic complications [15] [16]. 


\section{Conclusion}

In view of the epidemiological transition of cardiovascular diseases in Africa, the results of this study show a great deal of inadequacy among physicians with regard to knowledge, attitudes and practices in the management of hypertension. The focus must be on continuing education, with a view to improve the quality of care, create poles for the management of hypertension with hypertension specialists and ensure coordination between medical specialists and generalists for better patient management.

\section{Conflicts of Interest}

The authors declare no conflicts of interest regarding the publication of this paper.

\section{References}

[1] Traore, A. (1999) Aspects épidémiologiques, cliniques et évolutifs immédiats de l'hypertension artérielle maligne dans le service de cardiologie de l'hôpital du point G. Thèse, Méd, Bamako.

[2] Steichen, O. and Plouin, P.F. (2008) Traitement antihypertenseur prescrit aux patients avant leur première consultation dans un service spécialisé: Comparaison entre 2001-2006. La Revue de médecine interne, 29, 773-779. https://doi.org/10.1016/j.revmed.2008.01.002

[3] Denolle, T., Chamontin, B., Doll, G., Fauvel, J.P., Girerd, X., Herpin, D., et al. (2014) Prise en charge de l'hypertension artérielle résistante. Consensus d'experts de la Société française d'hypertension artérielle, filiale de la Société française de cardiologie. La Presse Médicale, 43, 1325-1331. https://doi.org/10.1016/j.lpm.2014.07.016

[4] Zahraoui, M. (2001) Prise en charge de l'hypertension artérielle par le médecin généraliste. Maghreb médical, 21, 69-72.

[5] Menta, I., Diall, I.B., Coulibaly, S., Ba, O., Sangare, I., Sidibe, N., et al. (2014) Pratiques et connaissances sur l'hypertension artérielle du personnel soignant des $\mathrm{CHU}$ Gabriel Touré et Point G. Mali Médical, Tome XXIX, No. 1, 21-28.

[6] Haute Autorité De Sante (2005) Synthèse des recommandations professionnelles, prise en charge des patients adultes atteints d'hypertension artérielle essentielle. https://www.has-sante.fr.1-6

[7] Dia, M.M., Hakim, R. and Diao, M. (2009) Enquête sur la prise en charge par les praticiens de l'hypertension artérielle systémique de l'adule au Sénégal. Congrès, SO.CAR. B.

[8] Atallah, V., Cornely, V., Grenié, E., Inamo, J., Carrère, P. and Atallah, A. (2016) Précarité, risque cardiovasculaire dans une population afrocaribéenne de SaintMartin. Données de l'étude CONSANT-SM. Annales de Cardiologie et d'Angéiologie, 65, 115-122. https://doi.org/10.1016/j.ancard.2016.04.002

[9] Bennis, A., Fadouach, S., Azouzi, L., Tahiri, A. and Chraibi, N. (1998) Les cardiologues Marocains face à l'hypertension artérielle. Annales de Cardiologie et d Angéiologie, 47, 555-562.

[10] Noubiap, J.J.N., Jingi, A.M., Veigne, S.W., Onana, A.E., Yonta, E.W. and Kingue, S. (2014) Approach to Hypertension among Primary Care Physicians in the West Re- 
gion of Cameroon: Substantial Room for Improvement. Cardiovascular Diagnosis and Therapy, 4, 357-364.

[11] Rehman, A., Rehman, T., Shaikh, M.A. and Naqvi, S.A. (2011) Awareness of Hypertension among the Medical Students and Junior Doctors: A Multicenter Study from Pakistan. Journal of Pakistan Medical Association, 61, 1153-1157.

[12] Union Africaine (2013) Conférence des ministres de la santé de l'Union Africaine, incidence des maladies non transmissibles et des maladies tropicales négligées sur le développement en Afrique; Etat de l'hypertension en Afrique; CAMH/Exp/6 (VI), AddisAbeba, 1-3.

[13] Godeau, P., Herson, S. and Piette, J.C. (2004) Traité de médecine: Hypertension artérielle, Tome 1, Flammarion, Paris, 1-96.

[14] Milon, H. (2000) Recommandations pour la pratique clinique: Prise en charge des patients adultes atteints d'hypertension artérielle essentielle. Paris, 1-17. https://www.anaes.fr/www.sante.fr

[15] Ouologueme, N. (2005) Place de l'hypertension artérielle dans la pathologie cardio-vasculaire dans le district de Bamako en 2002. Thèse, Méd, Bamako.

[16] Steichen, O. and Plouin, P.F. (2014) Prise en charge actuelle de l'hypertension artérielle. La Revue de médecine interne, 35, 235-242.

https://doi.org/10.1016/j.revmed.2013.06.013 